\title{
Recurrent laryngeal nerve monitoring during totally robot-assisted Ivor Lewis esophagectomy
}

\author{
J. I. Staubitz ${ }^{1}$ P. C. van der Sluis ${ }^{1}$ - F. Berlth ${ }^{1}$ - F. Watzka ${ }^{1}$ - F. Dette ${ }^{2} \cdot$ A. Läßig ${ }^{3} \cdot$ H. Lang ${ }^{1} \cdot$ T. J. Musholt ${ }^{4}$. \\ P. P. Grimminger ${ }^{1}$ (D)
}

Received: 6 July 2020 / Accepted: 10 September 2020 / Published online: 24 September 2020

(C) The Author(s) 2020

\begin{abstract}
Purpose The robot-assisted approach for Ivor Lewis esophagectomy offers an enlarged, three-dimensional overview of the intraoperative situs. The vagal nerve (VN) can easily be detected, preserved, and intentionally resected below the separation point of the recurrent laryngeal nerve (RLN). However, postoperative vocal cord paresis can result from vagal or RLN injury during radical lymph node dissection, presenting a challenge to the operating surgeon.

Methods From May to August 2019, 10 cases of robot-assisted minimally invasive esophagectomy (RAMIE) with extended 2-field lymphadenectomy, performed at the University Medical Center Mainz, were included in a prospective cohort study. Bilateral intermittent intraoperative nerve monitoring (IONM) of the RLN and VN was performed, including pre- and postoperative laryngoscopy assessment. Results Reliable mean signals of the right VN $(2.57 \mathrm{mV} / 4.50 \mathrm{~ms})$ and the RLN (left $1.24 \mathrm{mV} / 3.71 \mathrm{~ms}$, right $0.85 \mathrm{mV} / 3.56 \mathrm{~ms}$ ) were obtained. IONM facilitated the identification of the exact height of separation of the right RLN from the VN. There were no cases of permanent postoperative vocal paresis. Median lymph node count from the paratracheal stations was 5 lymph nodes. Conclusion IONM was feasible during RAMIE. The intraoperative identification of the RLN location contributed to the accuracy of lymph node dissection of the paratracheal lymph node stations. RLN damage and subsequent postoperative vocal cord paresis can potentially be prevented by IONM.
\end{abstract}

Keywords Esophageal cancer $\cdot$ Larynx $\cdot$ Robot-assisted surgery $\cdot$ Intraoperative nerve monitoring

\section{Introduction}

The use of intraoperative nerve monitoring (IONM) was shown to contribute to the identification of the recurrent

P. P. Grimminger

peter.grimminger@unimedizin-mainz.de

1 Department of General, Visceral and Transplantation Surgery, University Medical Center Mainz, Johannes Gutenberg University Mainz, Langenbeckstraße 1, 55131 Mainz, Germany

2 Department of Anesthesiology, University Medical Center, Johannes Gutenberg University Mainz, Langenbeckstraße 1, 55131 Mainz, Germany

3 Communication Disorders Division, Department of Otorhinolaryngology, University Medical Center Mainz, Johannes Gutenberg University Mainz, 55131 Mainz, Germany

4 Section of Endocrine Surgery, Department of General, Visceral and Transplantation Surgery, University Medical Center Mainz, Johannes Gutenberg University Mainz, Langenbeckstraße 1, 55131 Mainz, Germany laryngeal nerve (RLN) in different studies analyzing thyroidectomy, esophagectomy, and mediastinal lymph node dissection [1-3]. The reliable identification of the RLN is essential for an intentional preservation of the nerve during surgery. The DaVinci Xi robotic system offers an enlarged threedimensional view of the intraoperative situs during robotassisted esophagectomy for distal esophageal cancer, facilitating the identification of the vagal nerve (VN) without the support of IONM. Yet, the exact separation point of the RLN from the VN can be difficult to distinguish from the surrounding tissues, especially in cancer patients following neoadjuvant treatment. Vagal injury above this very point and damage of the RLN can lead to the development of vocal cord paresis (VCP). The risk of intraoperative damage is particularly high during lymphadenectomy along the RLN lymph node chain. Depending on the mechanism of injury, VCP can be transient or permanent. VCP is associated with a postoperatively elevated risk of aspiration pneumonia and voice impairment $[4,5]$. Furthermore, bilateral VCP can lead to a 
mechanically based respiratory insufficiency, which potentially requires tracheotomy $[4,5]$.

In open thoracic esophagectomy with extended 2-field lymphadenectomy, the use of RLN monitoring was described as a useful method, which leads to a reduction of cases with postoperative vocal cord paresis $[3,6]$. In minimally invasive (thoracoscopic) esophagectomy, the use of IONM for RLN detection before visual contact ("mapping") was proven to be associated with a reduction of the postoperative vocal cord paresis rate, when compared with esophagectomy without IONM support [7].

Nowadays, the interest in the use of robot-assisted minimally invasive esophagectomy (RAMIE) for esophageal cancer is increasing [8-10]. As an advantage over the aforementioned techniques, RAMIE allows for the dissection with 7 degrees of freedom, which is beneficial for a precise dissection of the esophagus and associated lymph node stations in the upper mediastinum $[11,12]$. Moreover, a more radical resection of upper mediastinal lymph nodes is facilitated by RAMIE, when compared with minimally invasive esophagectomy [13-16].

To our knowledge, the use of IONM in robot-assisted esophagectomy was not described before. The aim of this study was to document the feasibility of the IONM technique during a standardized totally robot-assisted Ivor Lewis esophageal resection with an extended 2-field lymph node dissection.

\section{Material and methods}

\section{Patients}

Patients with lower esophageal cancer and a preoperatively intact vocal cord function, treated at the University Medical
Center Mainz, were eligible for this prospective cohort study. Underlying histological entities were squamous cell carcinoma and adenocarcinoma with different localizations from the anterior dental row (Table 1). Patient- and treatment-related characteristics (tumor entity, TNM classification, and preoperative treatment) were prospectively collected in an institutional database. Initial staging included endoscopy combined with endoscopic ultrasonography and tumor biopsy as well as a thoracoabdominal computed tomography. Prior to treatment, all patients were discussed in an upper gastrointestinal multidisciplinary tumor board to determine optimal treatment. Standard neoadjuvant treatment for patients with esophageal adenocarcinoma was perioperative chemotherapy with FLOT (4 preoperative and 4 postoperative 2 -week cycles of docetaxel $50 \mathrm{mg} / \mathrm{m}^{2}$, oxaliplatin $85 \mathrm{mg} / \mathrm{m}^{2}$, leucovorin $200 \mathrm{mg} / \mathrm{m}^{2}$, and fluorouracil $2600 \mathrm{mg} / \mathrm{m}^{2}$ ), or CROSS chemoradiotherapy with carboplatin (area under the curve of $2 \mathrm{mg}$ per milliliter/ $\min )$ and paclitaxel $\left(50 \mathrm{mg} / \mathrm{m}^{2}\right.$ of body-surface area) for 5 weeks and concurrent radiotherapy (41.4 Gray in 23 fractions, 5 days per week) $[17,18]$ (Table 1). Postoperative follow up was carried out at the department's outpatient clinic. The study protocol conforms to the ethical guidelines of the 1975 Declaration of Helsinki (6th revision, 2008) as reflected in a priori approval by the institution's human research committee. Informed consent was obtained from all participants.

\section{Technique of IONM}

Intraoperative nerve monitoring of the recurrent laryngeal nerve and the vagal nerve is a standard procedure in thyroid surgery at the University Medical Center Mainz. It was newly introduced also for oncological esophagus surgery (especially

Table 1 Patient characteristics

\begin{tabular}{|c|c|c|c|c|}
\hline Patient & Histology & TNM Classification [41] & Preoperative treatment & Localization $(\mathrm{cm})^{\mathrm{a}}$ \\
\hline 1 & ESCC & pT3, pN2 (3/53), L0, V1, Pn0 & none & $30-\mathrm{x}$, stenosis \\
\hline 2 & EAC & ypT1b, ypN3 (8/28), L0, V0, Pn0 & CROSS $^{\mathrm{b}}$ & $38-41$ \\
\hline 3 & EAC & урT2, ypN0 (0/32), L0, V0, Pn0 & DANTE $^{\mathrm{c}}$ & $33-37$ \\
\hline 4 & EAC & урT3, урN1 (1/81), L0, V0, Pn0 & FLOT $^{\mathrm{d}}$ & $31-42$ \\
\hline 5 & ESCC & pT3, pN1 (1/22), L1, V0, Pn1 & none & $30-32$ \\
\hline 6 & EAC & pT1a, pN0 (0/50), L0, V0, Pn0 & FLOT $^{d}$ & $35-42$ \\
\hline 7 & EAC & ypT3, ypN3 (8/35), L0, V0, Pn0 & CROSS $^{\mathrm{b}}$ & $36-42$ \\
\hline 8 & ESCC & ypTis, pN0 (0/33), L0, V0, Pn0 & CROSS $^{\mathrm{b}}$ & $26-32$ \\
\hline 9 & ESCC & урT0, pN0 (0/38), L0, V0, Pn0 & CROSS $^{\mathrm{b}}$ & $28-30$ \\
\hline 10 & ESCC & ypT3, pN0(0/30), L0, V0, Pn0 & CROSS $^{\mathrm{b}}$ & $28-30$ \\
\hline
\end{tabular}

$E A C$ esophageal adenocarcinoma, $E S C C$ esophageal squamous cell carcinoma

${ }^{\text {a }}$ From anterior dental row in preoperative endoscopy

${ }^{\mathrm{b}}$ CROSS (41.4Gy plus carboplatin/paclitaxel) [18]

${ }^{\mathrm{c}}$ FLOT (5-fluorouracil/calciumfolinate/oxaliplatin/docetaxel) + atezolizumab, DANTE study

${ }^{\mathrm{d}}$ FLOT (5-fluorouracil/calciumfolinate/oxaliplatin/docetaxel) [17] 
RAMIE), in order to facilitate the detection of the recurrent laryngeal nerve during lymph node dissection in the upper mediastinum. Whereas for thyroid surgery continuous nerve monitoring is performed [4, 19] - allowing for an immediate feedback of an impaired nerve function due to an operation maneuver - for the present study in esophagus surgery, intraoperative nerve monitoring (IONM) was used to locate the recurrent laryngeal nerve by intermittent nerve stimulation. Nerve stimulation was performed with $7 \mathrm{~Hz}, 200 \mu \mathrm{s}, 2 \mathrm{~mA}$.

\section{Perioperative management}

One day preoperatively, at the Department of Otorhinolaryngology of the University Medical Center Mainz, patients underwent a standardized videolaryngeoscopic evaluation of the vocal cord function, including photo documentation. In preparation for surgery, gastroscopy with pylorus dilatation was conducted to prevent postoperative delayed gastric emptying [20]. All patients received an epidural catheter and were intubated with a double-lumen tube. Antibiotic prophylaxis (ampicillin $2000 \mathrm{mg}$ and sulbactam $1000 \mathrm{mg}$ ) was administered $30 \mathrm{~min}$ prior to incision. Postoperatively, extubation took place in the operation theater. All patients were admitted to the intensive care unit (minimum observation time: one night postoperatively). A postoperative laryngoscopy control was performed before discharge from hospital.

\section{Surgery}

As previously described by our group, totally robot-assisted Ivor Lewis esophageal resection with extended 2-field lymphadenectomy using Da Vinci Xi (Intuitive Surgical Inc., Sunnyvale, CA, USA) was performed as a modification of the original RAMIE technique $[8,21]$. This procedure was shown to be technically feasible and safe [8]. All operations were carried out by one surgeon, ensuring a high comparability between the single interventions.

\section{RAMIE-abdominal phase}

The patient was placed in supine position. The lesser omentum was transected up to the left crus of the diaphragm. Then, the greater gastric curvature was dissected using a harmonic ace. An abdominal lymphadenectomy was performed including lymph nodes at the celiac trunk, along the left gastric and splenic artery and including the lesser omentum. The left gastric artery and vein were transected following ligation with Hem-o-lok (Teleflex Medical, Weck Driv, NC, USA).

\section{RAMIE-thoracic phase}

The patient was positioned in the left lateral decubitus position, tilted $45^{\circ}$ towards the prone position. The robotic system was located at the dorsocranial side of the patient. Four ports were placed for the robot-assisted system and one thoracoscopic port for the assisting surgeon. After selective desufflation of the right lung, the pulmonary ligament was divided. Then, the parietal pleura was dissected at the anterior side of the esophagus from the diaphragm up to the azygos arch. The azygos vein was transsected following ligation with Hem-o-lok (Teleflex Medical, Weck Driv, NC, USA). Dissection of the parietal pleura was continued above the azygos arch for a dissection of the right paratracheal lymph nodes. Intraoperative nerve monitoring of the right $\mathrm{VN}$ and RLN was performed (Fig. 1a). At the posterior side of the esophagus, the parietal pleura was dissected from cranially to caudally along the azygos vein, including the thoracic duct. The thoracic duct was clipped with a 10-mm endoscopic clipping device (EndoclipTM II; Covidien, Mansfield, Massachusetts, USA). Lymph node dissection was continued in the left paratracheal region, complemented by IONM "mapping" of the left RLN (Fig. 1b). The esophagus was resected en bloc with the surrounding mediastinal and paratracheal lymph nodes. The resected specimen contained right-sided paratracheal (lymph node station 2R), left-sided paratracheal (lymph node station 2L) tracheobronchial (lymph node station 4), aortopulmonary window (station 5), and carinal (station 7) and peri-esophageal (station 8) lymph nodes [22, 23].

\section{RAMIE-application of IONM}

IONM signal registration was facilitated by non-invasive endotracheal tube surface electrodes (Inomed $\mathrm{GmbH}$, Emmendingen, Germany), attached to the double-lumen tube (Mallinckrodt, Covidien, Dublin, Ireland: Fig. 2a). During intubation, the electrodes were positioned at the vocal cord level (Fig. 2b). A bipolar stimulation probe (7 Hz, $200 \mu \mathrm{s}, 2 \mathrm{~mA}$, Inomed $\mathrm{GmbH}$, Emmendingen, Germany) was introduced into the thoracic situs via an assistant port located in the fourth intercostal space, posterior axillary line. The stimulation probe was robotically positioned for intermittent nerve monitoring of the VN and for mapping of the RLN. IONM preceded the mobilization of the cranial portion of the esophagus and lymphadenectomy in the upper and lower paratracheal lymph node stations 2R, 2L, and 4 (Fig. 3). If required for a modification of the resection strategy, IONM mapping was repeated. In cases of particularly distal esophageal resection, singularly the left and right RLN were assessed. In these cases an assessment of the $\mathrm{VN}$ was not performed, since the additional preparation of the VN cranially to the operation site might have provoked unnecessary damage. Contemporaneous assessment of amplitude and latency was performed to characterize RLN and VN signals. 
Fig. 1 Intraoperative situs during robot-assisted Ivor Lewis esophagectomy (RAMIE). a Intraoperative situs with right recurrent laryngeal nerve and vagal nerve. b Situs with left recurrent laryngeal nerve during intermittent intraoperative nerve monitoring. Abbreviations: AV azygos vein, E esophagus, VN vagal nerve, RLN recurrent laryngeal nerve, VCS superior vena cava, PM trachea, pars membranacea
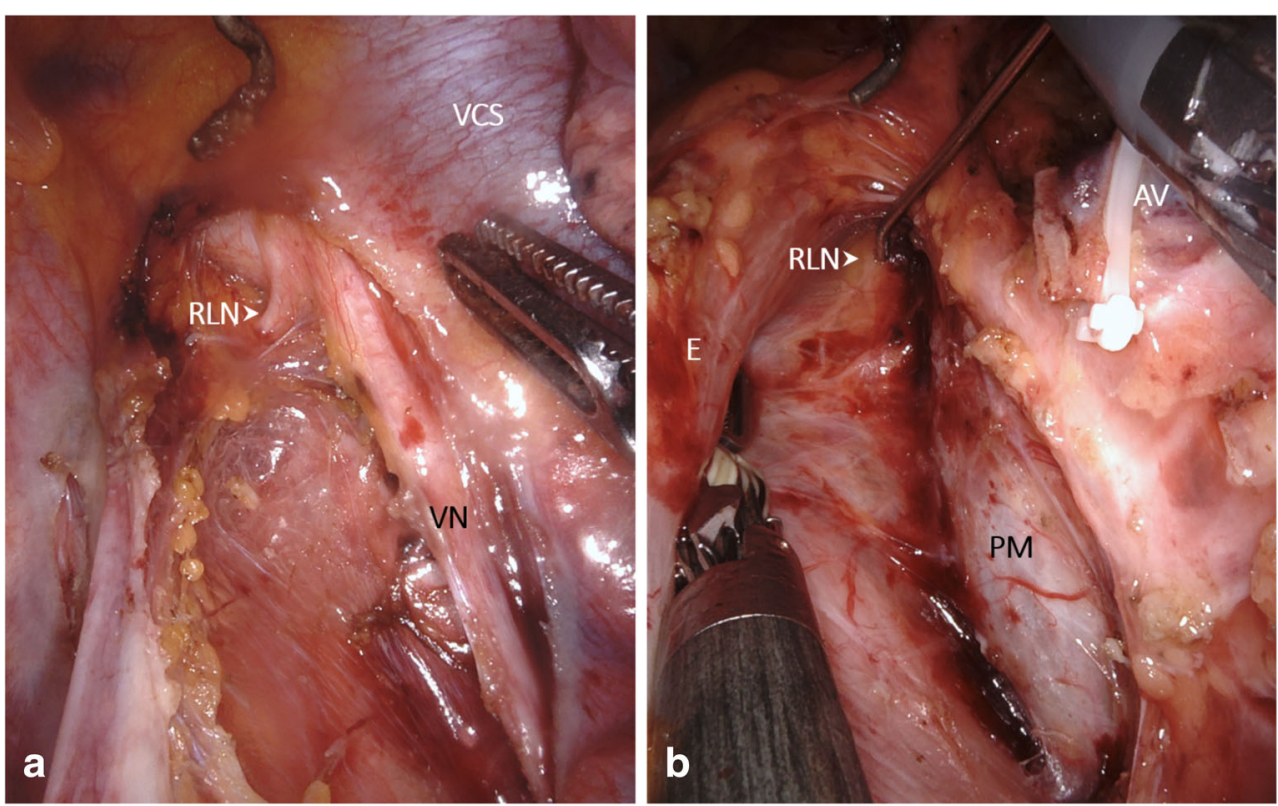

\section{Results}

In 10 patients with esophageal cancer, a totally robot-assisted 4-arm Ivor Lewis esophagectomy (RAMIE) with extended 2field lymphadenectomy and additional IONM was performed. Mean operation time was $326 \pm 37 \mathrm{~min}$. Mean operation time for the thoracic phase was $233 \pm 25 \mathrm{~min}$. The registration of IONM signals required between 2 and 4 min of the total operation time. IONM signals before esophageal resection are presented in Table 2. For the right VN, a mean signal amplitude of $2.57 \mathrm{mV}$ was calculated, with a mean latency of $4.50 \mathrm{~ms}$ (Table 2). An assessment of the left $\mathrm{VN}$ was not performed, since an additional preparation without benefit for the curative resection procedure would have been necessary. The mean values for amplitude and latency did not show significant differences between left and right RLN (mean amplitude $1.24 \mathrm{mV}$ left, $0.85 \mathrm{mV}$ right, mean latency $3.71 \mathrm{~ms}$ left, $3.56 \mathrm{~ms}$ right: Table 2). Tables 2 and 3 give an overview of the IONM signals obtained in the present study. The minimal differences in amplitudes and latency were caused by anatomical variation and differences in the preparation status of the tissue surrounding the analyzed nerves.
IONM facilitated the secure resection of upper and lower paratracheal lymph nodes in regions $2 \mathrm{R}, 2 \mathrm{~L}$, and 4 according to the American Thoracic Society [24]. The mean number of resected lymph nodes on final histology was 40 (median lymph node count 34 ). On average, $27 \%$ of these originated from the lymph node stations $2 \mathrm{R}, 2 \mathrm{~L}$, and 4 (median lymph node count 5). The postoperative laryngoscopy assessment showed normal vocal cord function in all cases.

\section{Discussion}

Nowadays, the rate of postoperative vocal cord paresis is considerable in esophagus surgery: from $1 \%$ up to $45.3 \%$ of patients undergoing esophagectomy (for squamous cell carcinoma, adenocarcinoma, and other cancer types) were reported to suffer from this complication [6, 25-28]. The VCP rate can be reduced by the choice of approach (open versus minimally invasive) and is dependent on the location of anastomosis [28]. For thyroid surgery, in which IONM represents a quality standard [4, 29], a rate of permanent VCP of roughly $1 \%$ is observed. Yet, thyroid redo-surgery leads to higher rates of
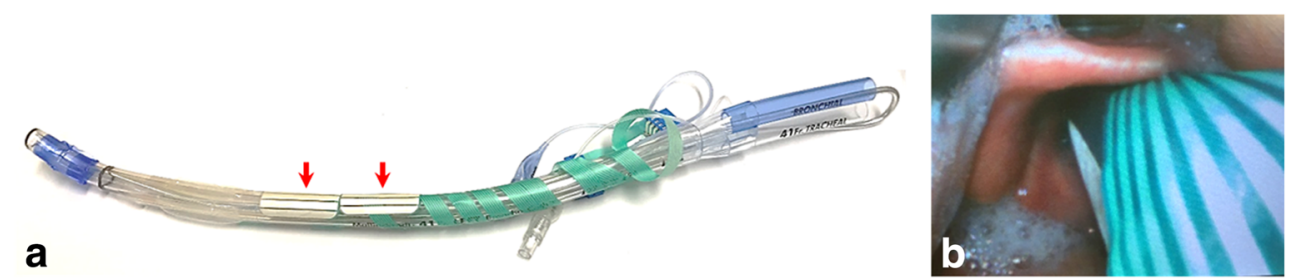

Fig. 2 Preparation of double-lumen tube with non-invasive surface electrodes. The endotracheal double-lumen tube is prepared with noninvasive surface electrodes (red arrows, a), which during intubation

using video laryngoscopy (C-MAC®, Karl Storz SE \& Co. KG, Tuttlingen, Germany) are positioned at the vocal cord level (b) 
Fig. 3 Scheme of intraoperative nerve monitoring (IONM) signals from the right vagal nerve (VN) and recurrent laryngeal nerve (RLN). IONM superior to the separation of the RLN from the VN (red arrow) leads to typical VN signals (1). The signal resulting from RLN stimulation (2) showed insignificantly lower amplitudes than the signal resulting from $\mathrm{VN}$ stimulation (1). VN stimulation after the separation from the RLN does not lead to measurable signals in IONM (3). Mean signal characteristics resulting from the current investigation are presented. Abbreviations: E esophagus, IONM intraoperative nerve monitoring, $\mathrm{VN}$ vagal nerve, RLN recurrent laryngeal nerve, $2 \mathrm{R}$ lymph node station $2 \mathrm{R}$ according to [24], 4R lymph node station $4 \mathrm{R}$ according to [24], 7 lymph node station 7 according to [24]
IONM signal

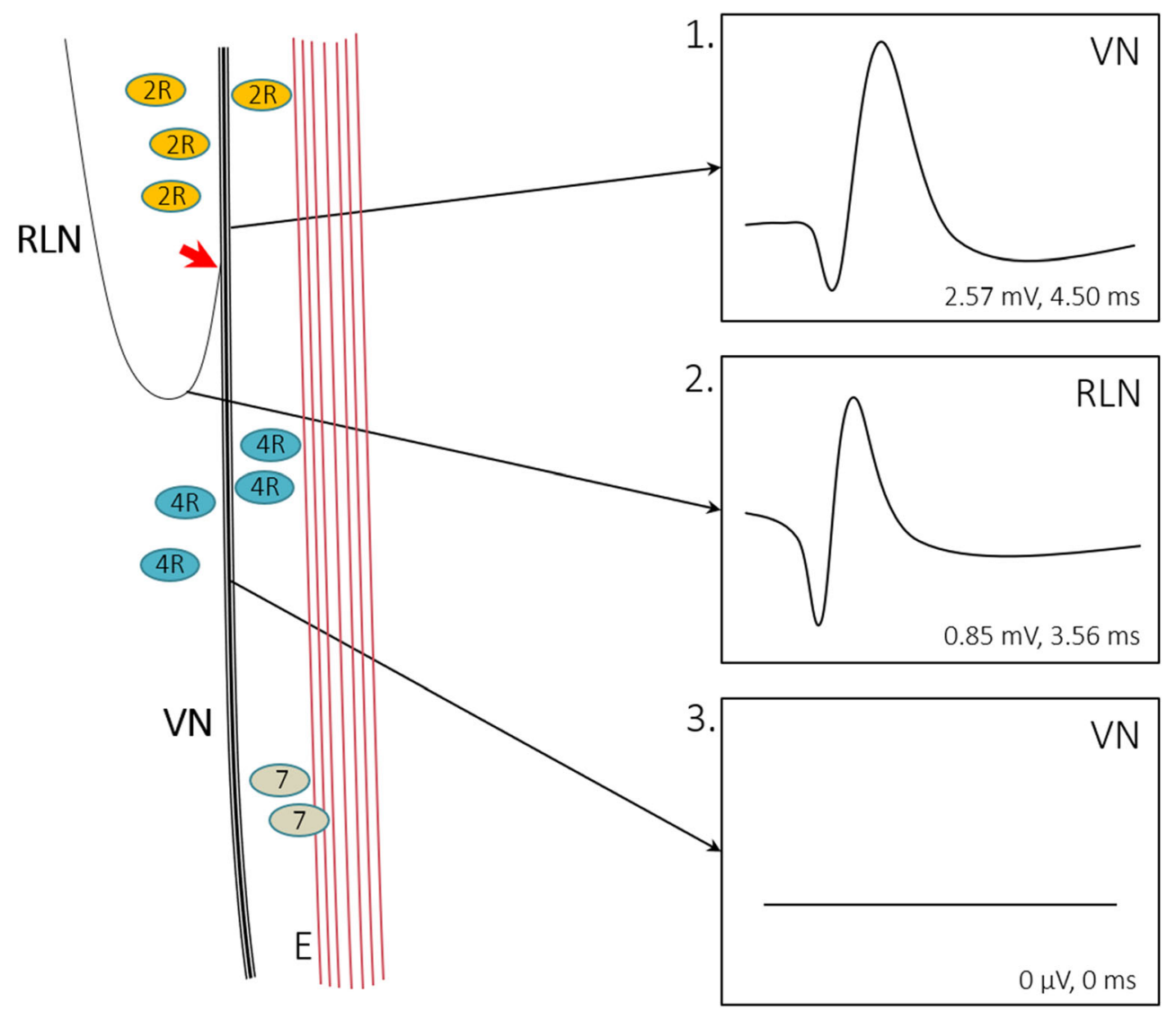

Table 2 Intraoperative nerve monitoring characteristics

\begin{tabular}{|c|c|c|c|c|c|c|c|c|}
\hline \multirow[t]{4}{*}{ Patients } & \multicolumn{8}{|c|}{ Signal before resection } \\
\hline & \multicolumn{4}{|l|}{ Vagal nerve } & \multicolumn{4}{|c|}{ Recurrent laryngeal nerve } \\
\hline & \multicolumn{2}{|l|}{ Left } & \multicolumn{2}{|l|}{ Right } & \multicolumn{2}{|l|}{ Left } & \multicolumn{2}{|l|}{ Right } \\
\hline & Amplitude (mV) & Latency (ms) & Amplitude (mV) & Latency (ms) & Amplitude (mV) & Latency (ms) & Amplitude (mV) & Latency (ms) \\
\hline 1 & - & - & 0.30 & 4.10 & 1.20 & 4.20 & 0.33 & 3.90 \\
\hline 2 & - & - & - & - & 1.62 & 3.80 & 1.20 & 3.20 \\
\hline 3 & - & - & - & - & 0.40 & 3.20 & 0.38 & 4.40 \\
\hline 4 & - & - & 0.52 & 3.50 & 0.19 & 3.70 & 0.52 & 3.30 \\
\hline 5 & - & - & 0.96 & 3.70 & 2.52 & 3.50 & 0.88 & 3.60 \\
\hline 6 & - & - & 13.90 & 9.90 & 0.80 & 3.50 & 0.55 & 3.30 \\
\hline 7 & - & - & 1.35 & 3.10 & 1.31 & 3.20 & 1.35 & 3.10 \\
\hline 8 & - & - & 0.55 & 4.10 & 0.60 & 4.20 & 0.63 & 3.90 \\
\hline 9 & - & - & 1.97 & 4.40 & 2.04 & 4.30 & 2.09 & 3.70 \\
\hline 10 & - & - & 1.00 & 3.20 & 1.74 & 3.50 & 0.58 & 3.20 \\
\hline Mean \pm SD & - & - & $2.57 \pm 4.61$ & $4.50 \pm 2.23$ & $1.24 \pm 0.71$ & $3.71 \pm 0.41$ & $0.85 \pm 0.55$ & $3.56 \pm 0.42$ \\
\hline
\end{tabular}

$S D$ standard deviation 
Table 3 Histopathological lymph node count

\begin{tabular}{|c|c|c|c|c|c|}
\hline Patients & $\begin{array}{l}1 \\
\text { Lymph node } \\
\text { count total }(\mathrm{N})\end{array}$ & $\begin{array}{l}2 \\
\text { Lymph nodes from lymph } \\
\text { node stations with anatomical } \\
\text { relation to the recurrent } \\
\text { laryngeal nerve, } 2 \mathrm{R}+ \\
2 \mathrm{~L}+4(N)[24]\end{array}$ & $\begin{array}{l}3 \\
\text { Percentage of lymph nodes } \\
\text { with anatomical relation to } \\
\text { the recurrent laryngeal nerve of } \\
\text { total lymph node count; } 2 / 1 \\
\text { (per cent) }\end{array}$ & $\begin{array}{l}4 \\
\text { Lymph nodes affected by } \\
\text { tumor in } 1(N, \text { per cent of } 1)\end{array}$ & $\begin{array}{l}5 \\
\text { Lymph nodes affected } \\
\text { by tumor in } 2 \\
(N, \text { per cent of } 2)\end{array}$ \\
\hline 1 & 53 & 14 & 26 & 3,6 & 0,0 \\
\hline 2 & 28 & 4 & 14 & 8,29 & 3,75 \\
\hline 3 & 32 & 4 & 13 & 0,0 & 0,0 \\
\hline 4 & 81 & 20 & 25 & 1,1 & 0,0 \\
\hline 5 & 22 & 3 & 14 & 1,5 & 0,0 \\
\hline 6 & 50 & 12 & 24 & 0,0 & 0,0 \\
\hline 7 & 35 & 3 & 9 & 8,23 & 2,67 \\
\hline 8 & 33 & 6 & 18 & 0,0 & 0,0 \\
\hline 9 & 38 & 6 & 16 & 0,0 & 0,0 \\
\hline 10 & 30 & 3 & 10 & 0,0 & 0,0 \\
\hline Mean \pm SD & $40( \pm 16)$ & $11( \pm 6)$ & 27 & $2( \pm 3)$ & $1( \pm 1)$ \\
\hline Median & 34 & 5 & 15 & 1 & 0 \\
\hline
\end{tabular}

$S D$ standard deviation

transient VCP in up to $12.5 \%$ and permanent lesions in $3.8 \%$ [30]. In esophageal surgery, the use of intraoperative nerve monitoring was shown to be associated with a reduction in the postoperative VCP rate, e.g., from 9.8 to $0 \%(p=0.029)$ in open surgery and 32.1 to $9.7 \%(p=0.03)$ in minimally invasive esophagectomy [6, 7]. In 2012, Zhong et al. reported an algorithm for IONM in open thoracic esophagectomy. "Step 1 " refers to testing the complete neural arch $(\mathrm{VN}+\mathrm{RLN})$ by stimulating the $\mathrm{VN}$ with signal retrieval at the vocal cord level. "Step 2" comprises the direct stimulation of the RLN. "Step 3" is a control of the RLN signal after resection, and "step 4" extends the post-resection control to the complete neural arch by another stimulation of the VN. This algorithm is similar to the systematic procedure recommended for IONM in thyroid and parathyroid surgery, which was published by the International Neural Monitoring Study Group in 2011 [31]. Yet, a pre- and postoperative laryngoscopy control was additionally recommended by Randolph et al. [31, 32]. In the present study on IONM during totally robot-assisted Ivor Lewis esophagectomy, we have performed pre- and postoperative laryngoscopy to assess the vocal cord function. However, we did not strictly adhere to the algorithm proposed by Zhong et al. in 2014. For this study, a pre-resection stimulation of the right VN including the mapping of the right RLN preceded the resection. Yet, if required by a modification of the resection strategy, we repeated IONM, to achieve an optimum localization of the RLN during the complete process of extended 2-field lymphadenectomy (Figs. 1 and 3). Even though the robot-assisted approach offers a precise overview of the intraoperative situs, in numerous cases, the left RLN is particularly difficult to distinguish from the surrounding tissues by the naked eye, underlining the utility of IONM mapping (Fig. 1b).

In the literature, different parameters were reported to influence the postoperative VCP rate resulting from esophagectomy. The left RLN was demonstrated to be the predominant localization of RLN injury [25]. It is plausible that the underlying anatomical location of the left RLN circumventing the aortic arch is responsible for this observation. Moreover, longer operation time and an advanced patient age were identified as significant independent predictors for VCP in esophagus surgery in multivariate analysis [25]. Furthermore, the use of continuous nerve monitoring in open esophageal resection with mediastinal lymphadenectomy was described [6]. The advantage of continuous nerve monitoring lies in the early discovery of a dissociation of amplitude and latency $[4,32,33]$. The dissociation illustrates an impeding loss of signal (LOS), potentially associated with postoperative VCP. Following an observed LOS, in thyroid surgery, an intended total thyroidectomy is recommended to be terminated after hemithyroidectomy, in order to avoid the potential risk of a bilateral VCP. A two-staged operation is the result, including rest-thyroidectomy after the certification of an intact vocal cord function by laryngoscopy in the meantime. In esophageal resection, the information about an intraoperative LOS cannot lead to a two-staged procedure. Yet, lymphadenectomy in the upper mediastinum can be modified. A reduction to unilateral, paratracheal lymphadenectomy can be considered in cases of LOS. Moreover, the postoperative management can be adapted to an observed LOS, i.e., a meticulous breathing therapy to prevent pneumonia can be exerted. VCP was demonstrated to significantly influence the risk of hospital readmission, dysphagia, 
hospitalization for lower respiratory tract infection, and gastrostomy/tracheostomy tube placement [5]. Since conventional continuous IONM with direct vagal stimulation would require an additional port during robot-assisted or minimally invasive esophagectomy, the non-invasive nerve monitoring making use of the laryngeal adductor reflex, as described by Sinclair et al. [34], is of particular interest.

The surgical radicality concerning the extent of lymphadenectomy differs between western countries and Asia. Whereas in the western world a comprehensive paratracheal lymphadenectomy is not yet commonly performed, in Asia, more radical approaches are applied [6]. The incidence of esophageal squamous carcinoma (ESCC) - the primary diagnosis in Asian countries - is relatively decreasing, whereas over the last decades, an increase in the incidence of esophageal adenocarcinoma (EAC) was observed [35, 36]. This increase primarily refers to western populations [35, 37]. In comparison to ESCC, EAC is diagnosed at higher tumor stages and is associated with earlier regional lymph node dissemination, a higher percentage of invaded lymph nodes and higher diffuse recurrence rates [38-40]. As a consequence, a comprehensive lymphadenectomy will gain more and more importance in the near future, also in western countries. In Asian studies, where RAMIE was compared with MIE, a higher mean lymph node yield along the recurrent laryngeal nerve was demonstrated in favor of RAMIE [13-15]. We also experienced the more radical resection of upper mediastinal lymph nodes during RAMIE in a cohort from the University Medical Center Mainz comparing robot-assisted minimally invasive esophagectomy with conventional minimally invasive esophagectomy (MIE) in a propensity-matched analysis [16].

A shift from MIE towards RAMIE can therefore be expected. The further use of IONM, e.g., as reported by Zhong et al. in 2012 in open thoracic surgery, can contribute to a reduction of resulting vocal cord paresis rates and associated postoperative morbidity. Based on the results of the present study, at the University Medical Center Mainz, IONM is performed regularly in patients undergoing RAMIE with lymphadenectomy along the recurrent laryngeal nerve lymph node chain. We experienced the application of IONM to locate the RLN as a useful addition, allowing for a safe and precise resection of the lymph nodes in the regions $2 \mathrm{R}, 2 \mathrm{~L}$, and 4 according to the American Thoracic Society [24]. An analysis of a potential reduction of the postoperative VCP rate is currently under preparation.

\section{Conclusion}

The present study illustrates that intraoperative nerve monitoring is feasible during totally robot-assisted minimally invasive esophagectomy with extended 2-field lymphadenectomy. The intraoperative identification of the location of the recurrent laryngeal nerve by IONM contributed to the accuracy of lymph node dissection of the paratracheal lymph node stations. As damage of the recurrent laryngeal nerve (and therefore vocal cord paralysis) was absent in the present cohort, it can be deduced that intraoperative nerve monitoring contributes to a prevention of the recurrent laryngeal nerve during RAMIE.

Code availability Not applicable.

Authors' contributions JIS - study conception and design, acquisition of data, analysis and interpretation of data, drafting of manuscript. PCS acquisition of data, analysis and interpretation of data, drafting of manuscript, critical revision of manuscript. FB - analysis and interpretation of data, critical revision of manuscript. FW-analysis and interpretation of data, critical revision of manuscript. FD - acquisition of data. ALacquisition of data. HL - critical revision of manuscript. TJM — study conception and design, critical revision of manuscript. PPGacquisition of data, study conception and design, critical revision of manuscript.

Funding Open Access funding enabled and organized by Projekt DEAL.

Data availability All data are explicitly shown in tables.

\section{Compliance with ethical standards}

Conflict of interest No financial or other interest with regard to the submitted manuscripts might be construed as a conflict of interest. Peter P. Grimminger is proctor for Intuitive Surgical. All the co-authors have nothing to disclose; neither received funding. The authors also had freedom of investigation and full control of the design of the study, the methods used, the outcome parameters and results, the analysis of data, and the production of the written report.

Open Access This article is licensed under a Creative Commons Attribution 4.0 International License, which permits use, sharing, adaptation, distribution and reproduction in any medium or format, as long as you give appropriate credit to the original author(s) and the source, provide a link to the Creative Commons licence, and indicate if changes were made. The images or other third party material in this article are included in the article's Creative Commons licence, unless indicated otherwise in a credit line to the material. If material is not included in the article's Creative Commons licence and your intended use is not permitted by statutory regulation or exceeds the permitted use, you will need to obtain permission directly from the copyright holder. To view a copy of this licence, visit http://creativecommons.org/licenses/by/4.0/.

\section{References}

1. Calò PG, Pisano G, Medas F, Pittau MR, Gordini L, Demontis R, Nicolosi A (2014) Identification alone versus intraoperative neuromonitoring of the recurrent laryngeal nerve during thyroid surgery: experience of 2034 consecutive patients. J Otolaryngol Head Neck Surg 43(1):16. https://doi.org/10.1186/1916-0216-4316

2. Hermann M, Hellebart C, Freissmuth M (2004) Neuromonitoring in thyroid surgery: prospective evaluation of intraoperative electrophysiological responses for the prediction of recurrent laryngeal nerve injury. Ann Surg 240(1):9-17. https://doi.org/10.1097/01. sla.0000132260.34503.02 
3. Gelpke H, Grieder F, Decurtins M, Cadosch D (2010) Recurrent laryngeal nerve monitoring during esophagectomy and mediastinal lymph node dissection. World J Surg 34(10):2379-2382. https:// doi.org/10.1007/s00268-010-0692-0

4. Wu CW, Dionigi G, Barczynski M, Chiang FY, Dralle H, Schneider R, Al-Quaryshi Z et al (2018) International neuromonitoring study group guidelines 2018: part II: optimal recurrent laryngeal nerve management for invasive thyroid cancerincorporation of surgical, laryngeal, and neural electrophysiologic data. Laryngoscope 128(Suppl 3):S18-s27. https://doi.org/10. 1002/lary. 27360

5. Nouraei SAR, Allen J, Kaddour H, Middleton SE, Aylin P, Darzi A, Tolley NS (2017) Vocal palsy increases the risk of lower respiratory tract infection in low-risk, low-morbidity patients undergoing thyroidectomy for benign disease: a big data analysis. Clin Otolaryngol 42(6):1259-1266. https://doi.org/10.1111/coa.12913

6. Zhong D, Zhou Y, Li Y, Wang Y, Zhou W, Cheng Q, Chen L, Zhao J, Li X, Yan X (2014) Intraoperative recurrent laryngeal nerve monitoring: a useful method for patients with esophageal cancer. Dis Esophagus 27(5):444-451. https://doi.org/10.1111/j.14422050.2012.01414.x

7. Kobayashi H, Kondo M, Mizumoto M, Hashida H, Kaihara S, Hosotani R (2018) Technique and surgical outcomes of mesenterization and intra-operative neural monitoring to reduce recurrent laryngeal nerve paralysis after thoracoscopic esophagectomy: a cohort study. Int J Surg 56:301-306. https://doi.org/10. 1016/j.ijsu.2018.05.738

8. Grimminger PP, Hadzijusufovic E, Babic B, van der Sluis PC, Lang $\mathrm{H}$ (2019) Innovative fully robotic 4-arm Ivor Lewis esophagectomy for esophageal cancer (RAMIE4). Dis Esophagus. https://doi.org/ $10.1093 /$ dote/doz015

9. Huang L, Onaitis M (2014) Minimally invasive and robotic Ivor Lewis esophagectomy. J Thorac Dis 6 Suppl 3(Suppl 3):S314S321. https://doi.org/10.3978/j.issn.2072-1439.2014.04.32

10. Watson TJ (2008) Robotic esophagectomy: is it an advance and what is the future? Ann Thorac Surg 85(2):S757-S759. https:// doi.org/10.1016/j.athoracsur.2007.11.046

11. Boone J, Schipper ME, Moojen WA, Borel Rinkes IH, Cromheecke GJ, van Hillegersberg R (2009) Robot-assisted thoracoscopic oesophagectomy for cancer. Br J Surg 96(8):878886. https://doi.org/10.1002/bjs.6647

12. van der Sluis PC, Ruurda JP, Verhage RJ, van der Horst S, Haverkamp L, Siersema PD, Borel Rinkes IH et al (2015) Oncologic long-term results of robot-assisted minimally invasive thoraco-laparoscopic esophagectomy with two-field lymphadenectomy for esophageal cancer. Ann Surg Oncol 22(Suppl 3):S1350 S1356. https://doi.org/10.1245/s10434-015-4544-x

13. Park S, Hwang Y, Lee HJ, Park IK, Kim YT, Kang CH (2016) Comparison of robot-assisted esophagectomy and thoracoscopic esophagectomy in esophageal squamous cell carcinoma J Thorac Dis 8 (10):2853-2861. doi:10.21037/jtd.2016.10.39

14. Chao YK, Hsieh MJ, Liu YH, Liu HP (2018) Lymph node evaluation in robot-assisted versus video-assisted thoracoscopic esophagectomy for esophageal squamous cell carcinoma: a propensitymatched analysis. World J Surg 42(2):590-598. https://doi.org/10. 1007/s00268-017-4179-0

15. Deng HY, Huang WX, Li G, Li SX, Luo J, Alai G, Wang Y, Liu LX, Lin YD (2018) Comparison of short-term outcomes between robot-assisted minimally invasive esophagectomy and videoassisted minimally invasive esophagectomy in treating middle thoracic esophageal cancer. Dis Esophagus 31(8). https://doi.org/10. 1093/dote/doy012

16. Tagkalos E, Goense L, Hoppe-Lotichius M, Ruurda JP, Babic B, Hadzijusufovic E, Kneist W, van der Sluis PC, Lang H, van Hillegersberg R, Grimminger PP (2019) Robot-assisted minimally invasive esophagectomy (RAMIE) compared to conventional minimally invasive esophagectomy (MIE) for esophageal cancer: a propensity-matched analysis. Dis Esophagus 33. https://doi.org/ $10.1093 /$ dote/doz060

17. Al-Batran SE, Homann N, Pauligk C, Goetze TO, Meiler J, Kasper S, Kopp HG et al (2019) Perioperative chemotherapy with fluorouracil plus leucovorin, oxaliplatin, and docetaxel versus fluorouracil or capecitabine plus cisplatin and epirubicin for locally advanced, resectable gastric or gastro-oesophageal junction adenocarcinoma (FLOT4): a randomised, phase $2 / 3$ trial. Lancet 393(10184):1948-1957. https://doi.org/10.1016/s0140-6736(18) 32557-1

18. van Hagen P, Hulshof MC, van Lanschot JJ, Steyerberg EW, van Berge Henegouwen MI, Wijnhoven BP, Richel DJ, Nieuwenhuijzen GA, Hospers GA, Bonenkamp JJ, Cuesta MA, Blaisse RJ, Busch OR, ten Kate F, Creemers GJ, Punt CJ, Plukker JT, Verheul HM, Spillenaar Bilgen EJ, van Dekken H, van der Sangen M, Rozema T, Biermann K, Beukema JC, Piet $\mathrm{AH}$, van Rij C, Reinders JG, Tilanus HW, van der Gaast A, CROSS Group (2012) Preoperative chemoradiotherapy for esophageal or junctional cancer. N Engl J Med 366(22):2074-2084. https://doi.org/10.1056/NEJMoa1112088

19. Schneider R, Randolph GW, Dionigi G, Wu CW, Barczynski M, Chiang FY, Al-Quaryshi Z et al (2018) International neural monitoring study group guideline 2018 part I: staging bilateral thyroid surgery with monitoring loss of signal. Laryngoscope 128(Suppl 3): S1-s17. https://doi.org/10.1002/lary.27359

20. Hadzijusufovic E, Tagkalos E, Neumann H, Babic B, Heinrich S, Lang H, Grimminger PP (2019) Preoperative endoscopic pyloric balloon dilatation decreases the rate of delayed gastric emptying after Ivor-Lewis esophagectomy. Dis Esophagus 32(6). https:// doi.org/10.1093/dote/doy097

21. Grimminger PP, Hadzijusufovic E, Ruurda JP, Lang H, van Hillegersberg R (2018) The da Vinci Xi robotic four-arm approach for robotic-assisted minimally invasive esophagectomy. Thorac Cardiovasc Surg 66(5):407-409. https://doi.org/10.1055/s-00381636933

22. Naruke T, Tsuchiya R, Kondo H, Nakayama H, Asamura H (1999) Lymph node sampling in lung cancer: how should it be done? Eur J Cardiothorac Surg 16(Suppl 1):S17-S24. https://doi.org/10.1016/ s1010-7940(99)00178-5

23. van der Sluis PC, van der Horst S, May AM, Schippers C, Brosens LAA, Joore HCA, Kroese CC, Haj Mohammad N, Mook S, Vleggaar FP, Borel Rinkes IHM, Ruurda JP, van Hillegersberg R (2019) Robot-assisted minimally invasive thoracolaparoscopic esophagectomy versus open transthoracic esophagectomy for resectable esophageal cancer: a randomized controlled trial. Ann Surg 269(4):621-630. https://doi.org/10.1097/sla. 0000000000003031

24. Murray JG, Breatnach E (1993) The American Thoracic Society lymph node map: a CT demonstration. Eur J Radiol 17(2):61-68. https://doi.org/10.1016/0720-048x(93)90037-n

25. Koyanagi K, Igaki H, Iwabu J, Ochiai H, Tachimori Y (2015) Recurrent laryngeal nerve paralysis after esophagectomy: respiratory complications and role of nerve reconstruction. Tohoku J Exp Med 237(1):1-8. https://doi.org/10.1620/tjem.237.1

26. Swanson SJ, Batirel HF, Bueno R, Jaklitsch MT, Lukanich JM, Allred E, Mentzer SJ et al (2001) Transthoracic esophagectomy with radical mediastinal and abdominal lymph node dissection and cervical esophagogastrostomy for esophageal carcinoma. Ann Thorac Surg 72(6):1918-1925. https://doi.org/10.1016/S00034975(01)03203-9

27. van Sandick JW, van Lanschot JJB, ten Kate FJW, Tijssen JGP, Obertop H (2002) Indicators of prognosis after transhiatal esophageal resection without thoracotomy for cancer. Journal of the American College of Surgeons 194(1):28-36 urn:nbn:nl:ui:29ce87358a-fe6c-4aec-b5fb-4a466e903130 
28. Oshikiri T, Nakamura T, Miura Y, Hasegawa H, Yamamoto M, Kanaji S, Yamashita K, Matsuda Y, Matsuda T, Sumi Y, Suzuki S, Kakeji Y (2017) Practical surgical techniques for lymphadenectomy along the right recurrent laryngeal nerve during thoracoscopic esophagectomy in the prone position. Ann Surg Oncol 24(8):2302. https://doi.org/10.1245/s10434-017-5879-2

29. Dralle H, Musholt TJ, Schabram J, Steinmuller T, Frilling A, Simon D, Goretzki PE et al (2013) German Association of Endocrine Surgeons practice guideline for the surgical management of malignant thyroid tumors. Langenbeck's Arch Surg 398(3):347-375. https://doi.org/10.1007/s00423-013-1057-6

30. Barczyński M, Konturek A, Pragacz K, Papier A, Stopa M, Nowak $\mathrm{W}$ (2014) Intraoperative nerve monitoring can reduce prevalence of recurrent laryngeal nerve injury in thyroid reoperations: results of a retrospective cohort study. World J Surg 38(3):599-606. https:// doi.org/10.1007/s00268-013-2260-x

31. Randolph GW, Dralle H, Abdullah H, Barczynski M, Bellantone R, Brauckhoff M, Carnaille B et al (2011) Electrophysiologic recurrent laryngeal nerve monitoring during thyroid and parathyroid surgery: international standards guideline statement. Laryngoscope 121(Suppl 1):S1-S16. https://doi.org/10.1002/lary.21119

32. Schneider R, Machens A, Randolph GW, Kamani D, Lorenz K, Dralle H (2017) Opportunities and challenges of intermittent and continuous intraoperative neural monitoring in thyroid surgery. Gland Surg 6(5):537-545. https://doi.org/10.21037/gs.2017.06.08

33. Schneider R, Randolph G, Dionigi G, Barczynski M, Chiang FY, Wu CW, Musholt T, Uludag M, Makay Ö, Sezer A, Teksöz S, Weber T, Sekulla C, Lorenz K, Özdemir M, Machens A, Dralle H (2019) Prediction of postoperative vocal fold function after intraoperative recovery of loss of signal. Laryngoscope 129(2):525531. https://doi.org/10.1002/lary.27327

34. Sinclair CF, Tellez MJ, Ulkatan S (2018) Noninvasive, tube-based, continuous vagal nerve monitoring using the laryngeal adductor reflex: feasibility study of 134 nerves at risk. Head Neck 40(11): 2498-2506. https://doi.org/10.1002/hed.25377

35. Zhang HZ, Jin GF, Shen HB (2012) Epidemiologic differences in esophageal cancer between Asian and Western populations. Chin J Cancer 31(6):281-286. https://doi.org/10.5732/cjc.011.10390

36. Shin A, Won YJ, Jung HK, Kong HJ, Jung KW, Oh CM, Choe S, Lee J (2018) Trends in incidence and survival of esophageal cancer in Korea: analysis of the Korea Central Cancer Registry database. J Gastroenterol Hepatol 33(12):1961-1968. https://doi.org/10.1111/ jgh.14289

37. Huang FL, Yu SJ (2018) Esophageal cancer: risk factors, genetic association, and treatment. Asian J Surg 41(3):210-215. https://doi. org/10.1016/j.asjsur.2016.10.005

38. Mariette C, Finzi L, Piessen G, Van Seuningen I, Triboulet JP (2005) Esophageal carcinoma: prognostic differences between squamous cell carcinoma and adenocarcinoma. World J Surg 29(1):39-45. https://doi.org/10.1007/s00268-004-7542-x

39. Siewert JR, Stein HJ, Feith M, Bruecher BL, Bartels H, Fink U (2001) Histologic tumor type is an independent prognostic parameter in esophageal cancer: lessons from more than 1,000 consecutive resections at a single center in the Western world. Ann Surg 234(3):360-367; discussion 368-369. https://doi.org/10.1097/ 00000658-200109000-00010

40. Siewert JR, Ott K (2007) Are squamous and adenocarcinomas of the esophagus the same disease? Semin Radiat Oncol 17(1):38-44. https://doi.org/10.1016/j.semradonc.2006.09.007

41. TNM Classification of Malignant Tumours (2017), vol 8th Edition. 8th Edition edn. Wiley-Blackwell,

Publisher's note Springer Nature remains neutral with regard to jurisdictional claims in published maps and institutional affiliations. 